\title{
An Artifact in Intracellular Cytokine Staining for Studying T Cell Responses and Its Alleviation
}

\section{OPEN ACCESS}

Edited by:

Elzbieta Kolaczkowska,

Jagiellonian University, Poland

Reviewed by:

Antonio Ferrante,

South Australia Pathology, Australia Jonathan Cools,

Montreal General Hospital, Canada

*Correspondence:

Guangwen Ren

Gary.Ren@jax.org

${ }^{\dagger}$ Lead Contact

Specialty section: This article was submitted to Cytokines and Soluble Mediators in Immunity, a section of the journal

Frontiers in Immunology

Received: 16 August 2021 Accepted: 04 January 2022

Published: 21 January 2022

Citation:

Gong Z, Li Q, Shi J and Ren G (2022) An Artifact in Intracellular Cytokine Staining for Studying T Cell Responses and Its Alleviation.

Front. Immunol. 13:759188. doi: 10.3389/fimmu.2022.759188

\author{
Zheng Gong ${ }^{1}$, Qing $L i^{1}$, Jiayuan Shi ${ }^{1}$ and Guangwen Ren ${ }^{1,2 * t}$ \\ 1 The Jackson Laboratory, Bar Harbor, ME, United States, ${ }^{2}$ The Jackson Laboratory Cancer Center, Bar Harbor, ME, United States
}

Intracellular cytokine staining (ICS) is a widely employed ex vivo method for quantitative determination of the activation status of immune cells, most often applied to T cells. ICS test samples are commonly prepared from animal or human tissues as unpurified cell mixtures, and cell-specific cytokine signals are subsequently discriminated by gating strategies using flow cytometry. Here, we show that when ICS samples contain Ly6G neutrophils, neutrophils are ex vivo activated by an ICS reagent - phorbol myristate acetate (PMA) - which leads to hydrogen peroxide $\left(\mathrm{H}_{2} \mathrm{O}_{2}\right)$ release and death of cytokineexpressing $T$ cells. This artifact is likely to result in overinterpretation of the degree of $\mathrm{T}$ cell suppression, misleading immunological research related to cancer, infection, and inflammation. We accordingly devised easily implementable improvements to the ICS method and propose alternative methods for assessing or confirming cellular cytokine expression.

Keywords: intracellular cytokine staining, neutrophils, cancer, inflammation, immunosuppression, hydrogen peroxide

\section{INTRODUCTION}

Intracellular cytokine staining (ICS) is a prevailing method for measuring cytokine expression in immune cells at the single cell level, especially $\mathrm{T}$ cells (1). The test samples typically undergo a short period ( 3-6 hours) of ex vivo activation by mitogens or antigens, which elicit primary cytokine production in immune cells mimicking physiological conditions (2). The presence of protein transport 
inhibitors, such as brefeldin A, limits cytokine localization to the rough endoplasmic reticulum, enabling subsequent immunostaining and intracellular cytokine detection upon sample fixation and permeabilization (1). As ICS permits simultaneous detection of multiple cytokine signals within a single cell, it has been widely adopted in the research fields of infection, inflammation, and cancer for quantitative analysis of immune responses (1).

To better capture the in vivo activation status of immune cells, freshly dissociated cells from animal or human crude tissues are commonly used in bulk for direct ICS tests. Identification of the cytokine expression levels in specific cell types is then achieved via selective cell gating during flow cytometric analysis (1). We searched research papers published in select leading immunology journals in 2019-2020 and found that crude samples were used more often than purified cell samples in ICS analysis (Figure S1A). In particular, in recent COVID-19-related studies, crude clinical samples were predominantly employed for ICS (Figure S1A).

In the present work that determines the $\mathrm{T}$ cell responses under various inflammatory conditions, we found that when ICS samples contain neutrophils, one of the most abundant immune cells in human and animals (3), neutrophils are simultaneously activated by the $\mathrm{T}$ cell activation agent phorbol myristate acetate (PMA) ex vivo. The PMA-stimulated neutrophils release hydrogen peroxide $\left(\mathrm{H}_{2} \mathrm{O}_{2}\right)$, which in turn kills cytokine-expressing $\mathrm{T}$ cells during the initial step of ICS. This leads to an artifactual and inaccurate result of apparent robust $\mathrm{T}$ cell immunosuppression in crude samples containing neutrophils. We accordingly provided easily executed correction methods for ICS, and complementary methods in assessing and confirming cellular cytokine expression in immune cells.

\section{MATERIALS AND METHODS}

\section{Mice}

The animal study was reviewed and approved by the Institutional Animal Care and Use Committee at The Jackson Laboratory. C57BL/6J, BALB/cJ, IFN $\gamma$-YFP (C.129S4(B6)-Ifng $\left.g^{t m 3.1 L k y} / \mathrm{J}\right)$, Nox2 $2^{-/-}$(B6.129S-Cybb tm1Din $\left./ J\right)$, OT-1 (C57BL/6-Tg(TcraTcrb) $1100 \mathrm{Mjb} / \mathrm{J})$, OT-2 (B6.Cg-Tg(TcraTcrb)425Cbn/J) and humanized $\mathrm{CD}_{3}{ }^{+}$mice were obtained from The Jackson Laboratory (Bar Harbor, ME, USA).

\section{Tumor Cell Lines}

Mouse mammary cancer cell line 4T1 and human mammary cancer cell line MDA-MB-231 were purchased from American Type Culture Collection (ATCC; Manassas, Virginia, USA). The AT3 cell line was provided by S.I. Abrams (Roswell Park Comprehensive Cancer Center). The tumor cells were cultured in DMEM (Gibco, Thermo Fisher Scientific, Inc., Waltham, MA, USA) or RPMI-1640 (Gibco, Thermo Fisher Scientific, Inc., Waltham, MA, USA) supplemented with $10 \%$ fetal bovine serum (FBS) (Gemini Bio-Products, West Sacramento, CA, USA), 100 U/ $\mathrm{mL}$ penicillin, and $100 \mu \mathrm{g} / \mathrm{mL}$ streptomycin (Gibco, Thermo Fisher
Scientific, Inc., Waltham, MA, USA). All cells were cultured in a 5\% $\mathrm{CO}_{2}$ humidified incubator at $37^{\circ} \mathrm{C}$. All cell lines used in this study were determined to be negative for Mycoplasma prior to experiments. In order to overexpress mouse G-CSF, AT3 cells were infected with $g c s f$ (Csf3)-expressing lentivirus (the vector was a gift from R.A. Weinberg, Massachusetts Institute of Technology). AT3-gcsf construct positive cells were selected with G418 sulfate (Thermo Fisher Scientific, Inc., Waltham, MA, USA).

\section{In Vivo Tumor Implantation}

For orthotopic tumor formation, cultured tumor cells (at a density of $2 \times 10^{5}$ cells) were suspended in $10 \mu \mathrm{l}$ sterile PBS and injected into the fourth mammary fat pads of female BALB/cJ, IFN $\gamma$-YFP, C57BL/6J, Nox2 $2^{-/-}$or humanized CD $34^{+}$mice. Detection of the immune responses, including mouse or human cytokine-expressing $\mathrm{T}$ cells, were conducted at the early pre-metastatic stage when primary tumors were palpable (day 12 and 16 for the 4T1 and AT3/ AT3- $g c s f$ models, and day 30 for the MDA-MB-231 model).

\section{Tissue and Primary Tumor Dissociation}

The lung and primary tumors were collected from euthanized mice and cut into small pieces. Then the tissues were digested with $1 \mathrm{mg} / \mathrm{ml}$ collagenase IV (Thermo Fisher Scientific, Inc., Waltham, MA, USA) and $0.1 \mathrm{mg} / \mathrm{ml}$ DNase I (Sigma-Aldrich, St. Louis, MO, USA) in RPMI-1640 (10\% FBS) medium for 1 hour (tumor samples for 30 minutes) at $37^{\circ} \mathrm{C}$. Enzyme activity was neutralized by addition of medium and dissociated tissues were then filtered through $100 \mu \mathrm{m}$ cell strainers. The spleens were smashed using a syringe and the suspension was filtered with 70 $\mu \mathrm{m}$ cell strainers. The red blood cells were lysed using ACK lysis buffer (Thermo Fisher Scientific, Inc., Waltham, MA, USA) and all the single cells were then passed through $40 \mu \mathrm{m}$ cell strainers.

\section{T Cell Isolation and Neutrophil Depletion}

Pan T cells were isolated from spleen or lung cells in naïve or tumorbearing mice using anti-CD90.2 magnetic beads (Miltenyi Biotech, Auburn, CA, USA) according to the manufacturer's instructions. Neutrophils were depleted with anti-Ly6G MicroBeads (Miltenyi Biotech, Auburn, CA, USA). The purity of T cells and the efficiency of neutrophils depletion were analyzed with flow cytometry, which were above $90 \%$ and $99 \%$, respectively.

\section{Flow Cytometry and Intracellular Cytokine Staining}

For cell-surface staining, single cell suspensions were stained with fluorescent antibodies directly conjugated to cell surface markers. The cells were incubated for $30 \mathrm{~min}$ at $4^{\circ} \mathrm{C}$ and DAPI was added to indicate dead cells.

For intracellular cytokine staining, the cells were first incubated for 4 hours with $25 \mathrm{ng} / \mathrm{ml}$ PMA (Sigma-Aldrich, St. Louis, MO, USA), $1 \mu \mathrm{g} / \mathrm{ml}$ ionomycin (Sigma-Aldrich, St. Louis, MO, USA), and GolgiPlug (1:1000; BD Biosciences, San Jose, CA, USA) (with or without catalase, $1000 \mathrm{U} / \mathrm{ml}$ ) in a tissue culture incubator at $37^{\circ} \mathrm{C}$. Subsequently, Live/Dead Fixable stain BV510 (1:1000; Thermo Fisher Scientific, Inc., Waltham, MA, USA) was added to exclude dead cells. Surface antibodies were first stained, and cells were 
permeabilized and fixed using the Cytofix/Cytoperm kit (BD Biosciences, San Jose, CA, USA) according to the manufacturer's instructions. Then the intracellular proteins were stained with fluorescent antibodies. For the quantification of cell viability in ICS analysis, the $\alpha \beta \mathrm{T}$ cells or $\gamma \delta \mathrm{T}$ cells were firstly gated as $\mathrm{CD} 45^{+} \mathrm{CD} 3^{+} \mathrm{TCR}-\beta^{+}$or $\mathrm{CD} 45^{+} \mathrm{CD} 3^{+} \mathrm{TCR}-\gamma / \delta^{+}$, and the viable cells among them were further gated according to negative staining for Live/Dead Fixable stain BV510. Fluorescence intensity was measured on a Symphony A5 (BD Biosciences, San Jose, CA, USA) and data were analyzed by BD FACSDiVa software (version 8) or FlowJo Software (version 10.7.1). Fluorescenceactivated cell sorting (FACS) was performed on a FACSAria II (BD Biosciences, San Jose, CA, USA) cell sorter. All antibodies were purchased from Biolegend (San Diego, CA, USA).

To activate $\mathrm{T}$ cells with anti-CD3/anti-CD28, the crude lung or spleen samples were prepared from the orthotopic 4T1- or AT3/AT3-gcsf tumor bearing mice, and activated by plate-bound anti-CD3 (5 $\mu \mathrm{g} / \mathrm{ml}$; Bio X Cell, Lebanon, NH, USA) and soluble anti-CD28 ( $1 \mu \mathrm{g} / \mathrm{ml}$; Bio X Cell, Lebanon, NH, USA) for 24 hours at $37^{\circ} \mathrm{C}$. GolgiPlug (1:1000; BD Biosciences, San Jose, CA, USA) was added at the final 4 hours of incubation.

To activate $\mathrm{T}$ cells with specific antigen, the OT-1 or OT- 2 mice were orthotopically implanted with AT3 or AT3-gcsf tumor cells, and at day 16, the crude lung or spleen samples were harvested and activated by $\mathrm{OVA}_{257-264}$ peptide $(10 \mu \mathrm{g} / \mathrm{ml}$; In vivoGen, San Diego, $\mathrm{CA}, \mathrm{USA})$ or $\mathrm{OVA}_{323-339}$ peptide $(10 \mu \mathrm{g} / \mathrm{ml}$; In vivoGen, San Diego, CA, USA), respectively, for 24 hours at $37^{\circ} \mathrm{C}$. GolgiPlug (1:1000; BD Biosciences, San Jose, CA, USA) was added at the final 4 hours of incubation.

Mouse T cell panel: CD45-Alexa Flour 700 (Clone: 30-F11); CD3-APC (Clone: 17A2); TCR- $\beta$-APC/Fire 750 (Clone: H57597); TCR- $\gamma / \delta$-PE (Clone: UC7-13D5); IL-17A-Brilliant Violet 605 (Clone: TC11-18H10.1); IFN- $\gamma$-Brilliant Violet 711 (Clone: XMG1.2); IL-2- PE/Cyanine7 (Clone: JES6-5H4); TNF- $\alpha$ Brilliant Violet 421(Clone: MP6-XT22).

Mouse neutrophil panel: CD45-Alexa Flour 700 (Clone: 30F11); CD11b-Brilliant Violet 650 (Clone: M1/70); Ly-6C-Brilliant Violet 570 (Clone: HK1.4); Ly-6G-Pacific Blue (Clone: 1A8).

Human T cell panel: CD45-Alexa Flour 700 (Clone: 2D1); CD3APC (Clone: OKT3); IL-17A-Brilliant Violet 605 (Clone: BL168); IFN- $\gamma$-Brilliant Violet 711 (Clone: 4S.B3); IL-2- PE/Cyanine7 (Clone: MQ1-17H12); TNF- $\alpha$-Brilliant Violet 421(Clone: MAb11).

Human neutrophil panel: CD45-Alexa Flour 700 (Clone: 2D1); CD33-PE/Cyanine5 (Clone: WM53); CD15-Brilliant Violet 650 (Clone: W6D3); CD66b-PerCP/Cyanine5.5 (Clone: G10F5).

\section{RNA Extraction and qRT-PCR}

Total RNA was isolated using the Direct-zol RNA Miniprep Plus Kit (Zymo-Research, Irvine, CA, USA) according to the manufacturer's instructions. cDNA was synthesized from RNA with the High-Capacity cDNA Reverse Transcription Kit (Thermo Fisher Scientific, Inc., Waltham, MA, USA). qRT-PCR was carried out on the ViiA 7 Real-Time PCR System (Thermo Fisher Scientific, Inc., Waltham, MA, USA) by using PowerUp SYBR Green PCR Master Mix (Thermo Fisher Scientific, Inc., Waltham, MA, USA). Relative mRNA expression was calculated using the comparative CT method $(\Delta \Delta \mathrm{Ct})$ normalized to housekeeping gene Rps18.
Primer sequences were listed below:

Rps18 forward, 5'- GGAGAACTCACGGAGGATGA -3', Rps18 reverse, 5'- CCAGTGGTCTTGGTGTGCTG -3' Ill7a forward, 5' - CTCCAGAAGGCCCTCAGACTAC -3', Ill7a reverse, 5'- AGCTTTCCCTCCGCATTGACACAG -3' Ifng forward, 5' - GGCCATCAGCAACAACATAAGCGT -3', Ifng reverse, 5'- TGGGTTGTTGACCTCAAACTTGGC -3' $\operatorname{Prd} x 1$ forward, 5'- GTTGGCCGCTCTGTGGATGAGAT -3', $\operatorname{Prd} 1 \times 1$ reverse, 5' - ATCACTGCCAGGTTTCCAGCCAGC -3' $\operatorname{Prd} 2 \times 2$ forward, 5'- GTTCTCCGGCCTAGGGCTCTCTC -3', $\operatorname{Prd} d x 2$ reverse, 5'- GCCGGAGGCCATGACTGCGTG -3' Txn2 forward, 5'- CGACCTTTAACGTCCAGGATG -3', Txn2 reverse, 5' - ACTGTGCATGAAAGTCCACAAC -3' Mdh2 forward, 5'- TGACCTGTTCAACACCAACG -3', Mdh2 reverse, 5'- GATGGGGATGGTGGAGTTC -3' Sod 1 forward, 5'- TACTGATGGACGTGGAACCC -3', Sod1 reverse, 5' - GAACCATCCACTTCGAGCA -3' $\mathrm{Nfe} 2 \mathrm{l} 2$ forward, 5'- GCAGCCATGACTGATTTAAGC -3', Nfe2l2 reverse, 5' - CAGCCAGCTGCTTGTTTTC -3' Gclm forward, 5'- AGGAGCTTCGGGACTGTATCC -3', Gclm reverse, 5'- GGGACATGGTGCATTCCAAAA -3' Pgd forward, 5' - ATGGCCCAAGCTGACATTG -3', Pgd reverse, 5'- GCACAGACCACAAATCCATGAT -3' Gpx1 forward, 5' - CAATGTAAAATTGGGCTCGAA -3', Gpx1 reverse, 5'- GTTTCCCGTGCAATCAGTTC -3' Gpx4 forward, 5' - TAAGAACGGCTGCGTGGT -3', Gpx4 reverse, 5'- GTAGGGGCACACACTTGTAGG -3

\section{Quantification of Hydrogen Peroxide}

Hydrogen peroxide $\left(\mathrm{H}_{2} \mathrm{O}_{2}\right)$ quantification was measured using an Amplex Red hydrogen peroxide/peroxidase assay kit (Invitrogen, Thermo Fisher Scientific, Inc., Waltham, MA, USA) according to the manufacturer's instructions. Briefly, the Amplex Red reagent/HRP working solution was added to each microplate well, and the suspension of isolated neutrophils or crude lung cells $\left(2 \times 10^{4}\right.$ cells) was added to the reaction mixture. Catalase $(1000 \mathrm{U} / \mathrm{ml})$ was mixed together with the suspension of cells. Reactions were incubated at room temperature for 30 minutes and fluorescence was measured using a microplate reader (SpectraMax i3, Molecular Devices, Sunnyvale, CA, USA) with excitation at $540 \mathrm{~nm}$ and emission at $590 \mathrm{~nm}$.

\section{$\mathrm{H}_{2} \mathrm{O}_{2}$ Susceptibility Assay}

Lung T cells were isolated from IFN $\gamma$-eYFP mice and stimulated with $25 \mathrm{ng} / \mathrm{ml} \mathrm{PMA}$ and $1 \mu \mathrm{g} / \mathrm{ml}$ ionomycin in the presence of GolgiPlug $(1: 1000)$ for 4 hours at $37^{\circ} \mathrm{C}$. Then the activated $\mathrm{T}$ cells were incubated with different concentrations of $\mathrm{H}_{2} \mathrm{O}_{2}$ at $37^{\circ} \mathrm{C}$ for 2 hours. Viable IFN $\gamma^{-}$or $\mathrm{IFN}^{+} \mathrm{T}$ cells were indicated as propidium iodide (PI) negative, and the absolute cell numbers were calculated using Precision Count Beads (Biolegend, San 
Diego, CA, USA) following the manufacturer's instructions. The fold change in viable cell numbers was normalized to the control group.

\section{Illustration Tool}

The schematic images are created with Biorender.com.

\section{Statistical Analysis}

Data are presented as mean \pm s.e.m. Statistical analyses were performed using GraphPad Prism version 8 software. We carried out unpaired two-tailed Student's $t$-test to compare two groups, and one-way ANOVA with Tukey's test to compare the variance in three or more groups with one independent factor. When there were effects of two factors on a dependent variable, two-way ANOVA with Šidák's multiple comparisons test was used. Statistical significance is indicated as $* P<0.05$, $* * P<0.01, * * * P<0.001, * * * * P<0.0001$, or NS (not significant).

\section{RESULTS}

\section{Contradictory Results Were Obtained in Evaluating T Cell Responses by ICS and Other Cytokine Detection Methods in the Mouse Model of Breast Cancer}

In our recent work, we performed ICS to determine IFN $\gamma$ expression, a common indicator of $\mathrm{T}$ cell responses (4), in crude spleen and lung tissue-dissociated cells as a means of assessing cancer-associated systemic immunosuppression at the early tumor progression stage. Using the mouse 4T1 orthotopic breast cancer model, a striking drop in IFN $\gamma^{+} \mathrm{T}$ cells was detected in both spleen and lungs of tumor-bearing mice (Figures 1A-C),
A

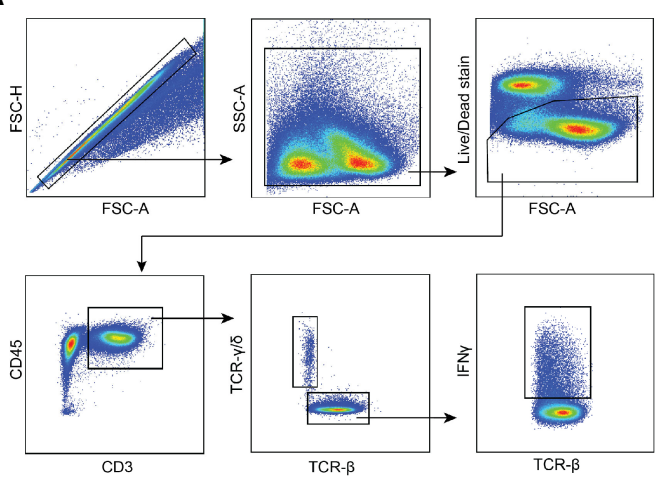

D

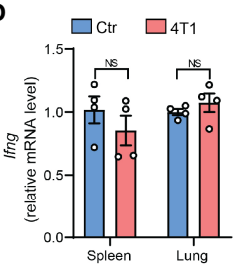

G

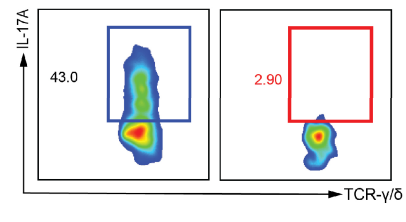

E

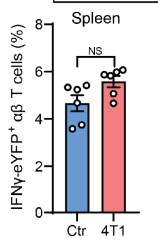

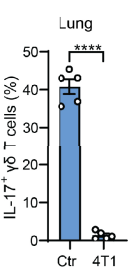

B

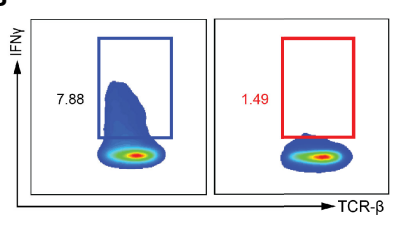

C

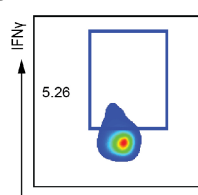

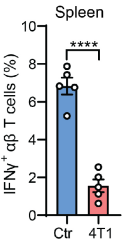
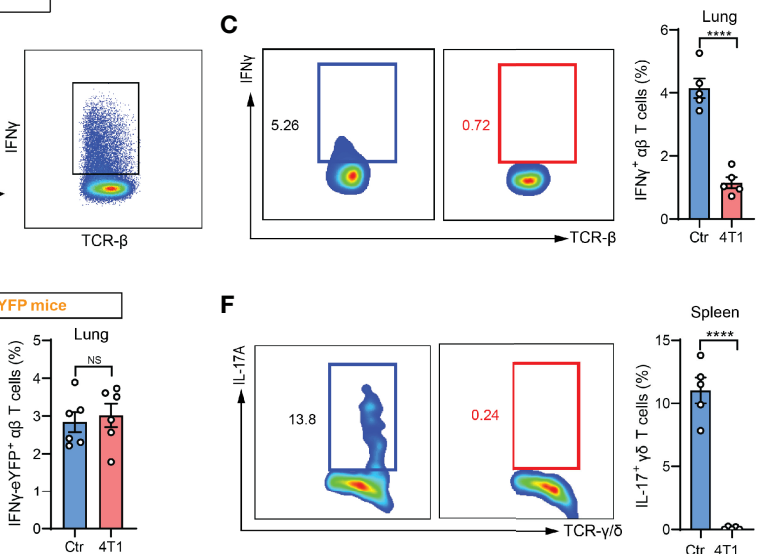

$\mathbf{F}$

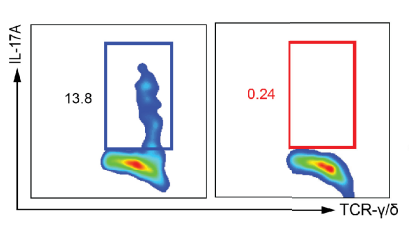

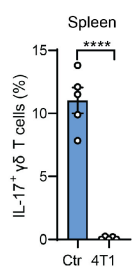

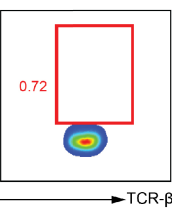

Ctr $4 \mathrm{~T} 1$

H $\square$ Ctr $\quad 4_{411} \quad$ I

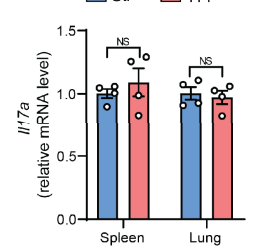

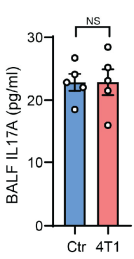

FIGURE 1 | A discrepancy was found between ICS and other cytokine detection methods in assessing T cell responses in the mouse model of breast cancer. (A) Gating strategy for spleen IFN $\gamma^{+} \alpha \beta$ T cells in flow cytometric analysis. Arrows indicate the parent population that the subsequent plots are gated on. (B, C) ICS analysis of the frequencies of IFN $\gamma^{+} \alpha \beta$ T cells in crude spleen (B) or lung (C) samples from naïve control (Ctr) or $4 \mathrm{~T} 1$ tumor-bearing mice ( $\mathrm{n}=5$ per group).

(D) Relative mRNA levels of Ifng in purified spleen or lung $\alpha \beta$ T cells from control or $4 \mathrm{~T} 1$ tumor-bearing mice ( $\mathrm{n}=4$ per group). (E) The frequencies of spleen or lung IFN $\gamma$-eYFP ${ }^{+} \alpha \beta$ T cells in control or 4T1 tumor-bearing mice ( $n=6$ per group) were quantified by living cell immunostaining and flow cytometry. (F, G) ICS analysis of the frequencies of IL-1 $17^{+} \gamma \delta \mathrm{T}$ cells in crude spleen $\mathbf{( F )}$ or lung (G) samples from control or $4 \mathrm{~T} 1$ tumor-bearing mice ( $\mathrm{n}=5$ per group). (H) Relative mRNA levels of II17a in purified spleen or lung $\gamma \delta \mathrm{T}$ cells from control or $4 \mathrm{~T} 1$ tumor-bearing mice ( $\mathrm{n}=4$ per group). (I) IL-17A levels in serum (left) or lung BALF (right) from control or $4 \mathrm{~T} 1$ tumor-bearing mice ( $\mathrm{n}=5$ per group) were measured by ELISA. Values of $\mathrm{n}$ represent biologically independent animals. Data are mean \pm s.e.m. $P$ values were calculated using unpaired t-test. ${ }^{\star \star \star \star} P<0.0001$. NS, not significant. 
which suggested tumor-elicited systemic immunosuppression. Surprisingly, this drastic tumor-associated T cell change was not detected when IFN $\gamma$ expression was measured by quantitative PCR (qPCR) in purified T cells (Figure 1D). To untangle these paradoxical results from ICS and qPCR assays, we next leveraged IFN $\gamma$-eYFP reporter mice (5), in which IFN $\gamma$ expression can be quantified by living cell immunostaining followed by flow cytometry instead of by ICS. The results were highly consistent with the qPCR assay, showing that the percentages of IFN $\gamma$ $\mathrm{eYFP}^{+} \mathrm{T}$ cells did not undergo changes with 4T1 tumor growth in either spleen or lungs (Figure 1E). These data indicated that contradictory conclusions can be drawn when testing cellular cytokine expression using different methods, and particularly, that there might be defects associated with ICS.

To tease out whether the discrepancy is specific for IFN $\gamma$, we next tested another widely studied inflammatory cytokine, IL-17, which is mainly produced by $\gamma \delta$-T cells in various types of inflammatory diseases $(6,7)$. Using the same $4 \mathrm{~T} 1$ model, a remarkable reduction in the percentages of IL- $17^{+} \gamma \delta$-T cells was found based on ICS analysis (Figures 1F, G), which was again not detected by $\mathrm{qPCR}$ in purified spleen or lung-derived $\gamma \delta$-T cells (Figure 1H), or by enzyme-linked immunosorbent assay (ELISA) in either serum or bronchoalveolar lavage fluid (BALF) (Figure 1I). The recurrent discord between ICS and other cytokine-determining approaches prompted us to reevaluate the application of ICS in assessing $\mathrm{T}$ cell cytokine expression using crude samples.

\section{Host Neutrophilia Contributes to the Artifact Associated With Crude Tissue Sample ICS Analysis in Tumor-Bearing Conditions}

The 4T1 breast tumor model is well known for induction of a profound host inflammation, characterized by a large expansion of neutrophils (neutrophilia) (Figures S1B, C), due to tumor-secreted hematopoietic growth factors (8). We thus speculated that neutrophils, a type of innate immune cell possessing non-specific cytotoxic effects (9), present in the crude tissue samples could react with $\mathrm{T}$ cells during the ex vivo activation process. Indeed, the IFN $\gamma$ and IL-17 suppression in T cells observed by crude cell ICS analysis was completely undetected by ICS when $\mathrm{Ly}_{6 \mathrm{G}}{ }^{+}$neutrophils were depleted from the crude samples (Figure 2A). Thus, the presence of neutrophils in ICS samples likely accounts for the artifact of T cell cytokine suppression.

To test the possibility that $\mathrm{Ly}_{6 \mathrm{G}}{ }^{+}$neutrophils directly interfere with T cells during the ICS procedure, crude lung samples freshly prepared from $4 \mathrm{~T} 1$ tumor-bearing mice were separated into ${\text { Ly } 6 \mathrm{G}^{+}}^{+}$neutrophils (Neu), CD45 ${ }^{+}$Ly6G $^{-}$leukocytes and nonleukocyte stromal cells $\left(\mathrm{CD} 45^{-}\right)$. These different cell subsets were then individually mixed with purified $\mathrm{T}$ cells and subjected to ICS analysis (Figure 2B, left). As expected, incubation with $\mathrm{Ly}_{6 \mathrm{G}^{+}}$neutrophils, but not $\mathrm{CD} 45^{+} \mathrm{Ly} 6 \mathrm{G}^{-}$leukocytes or CD 45 stromal cells, led to a prominent reduction of IFN $\gamma^{+}$and IL- $17^{+} \mathrm{T}$ cells (Figure 2B, middle and right). This ex vivo Ly6G ${ }^{+}$neutrophilmediated cytokine-expressing $\mathrm{T}$ cell suppression acted in a dosedependent manner (i.e., ratio of neutrophils to $\mathrm{T}$ cells) (Figure 2C), and was likely due to direct $\mathrm{T}$ cell killing
(Figures 2D and S1D). Therefore, during crude tissue sample ICS analysis, neutrophils existed in the samples will react with T cells during their ex vivo co-incubation resulting in an artifactual $\mathrm{T}$ cell suppression.

To validate this neutrophil-mediated artifact and to determine whether it is specific to the 4T1 tumor model, we next analyzed the AT3 and AT3-gcsf orthotopic breast tumor models. While AT3 induces marginal host neutrophilia, the AT3-gcsf line, which was constructed to overexpress a neutrophil growth factor granulocyte-colony stimulating factor (G-CSF) (10) - stimulates potent neutrophilia similar to the 4T1 model (Figures 2E and S1E). By comparing the AT3-gcsf and AT3 models, we were able to further confirm whether host neutrophilia causes the ICSassociated artifact. Using crude lung tissue samples, we expectedly observed a pronounced reduction of IFN $\gamma^{+}$and IL- $17^{+} \mathrm{T}$ cells in the AT3-gcsf tumor-bearing mice compared to the AT3-bearing or naïve control mice, by ICS (Figure 2F, left). However, such a host neutrophilia-associated T cell "suppression" was not detected by ICS analysis when using crude tissue samples depleted of Ly6G neutrophils, or using purified T cells (Figure 2F, middle and right, and Figure S2). These results clearly indicated that the ICS artifact in crude tissue sample analysis occurs when the host develops neutrophilia.

In addition to IFN $\gamma$ and IL-17, this $\mathrm{Ly}_{6} \mathrm{G}^{+}$neutrophil-induced artifactual effect was also found in ICS analysis of other T cell cytokines such as IL-2 and TNF $\alpha$ using crude tissue samples (Figure 2G). Moreover, the artifact similarly occurred in nonbreast cancer models such as mouse LLC lung carcinoma and MC38 colon adenocarcinoma (Figure S3), both of which induce host neutrophilia (Figure S4). Taken together, we conclude that host neutrophilia is a primary, if not exclusive, contributor to the artifact associated with crude tissue sample ICS analysis, and this issue can be resolved by $\mathrm{Ly}_{6 \mathrm{G}}{ }^{+}$neutrophil depletion or T cell purification.

\section{Hydrogen Peroxide $\left(\mathrm{H}_{2} \mathrm{O}_{2}\right)$ Is a Primary Mediator of the Neutrophil-Induced Artifact in ICS Analysis}

Serving as the essential part of the innate immunity, neutrophils represent one of the most abundant immune cells in animals and humans and play decisive roles in cancer, inflammation and infection (11). At the pathological sites, neutrophils are activated to exert their effector functions such as phagocytosis, degranulation, formation of neutrophil extracellular traps (NETs), and release of reactive oxygen species (ROS) (12). Among these effects, ROS are cytotoxic to both pathogens and the host cells, which partially accounts for the reported dual beneficial and potentially detrimental roles of neutrophils in host defense, tissue damage, and inflammatory diseases $(13,14)$. We then suspected that the cytotoxic ROS from neutrophils could mediate the killing of cytokine-expressing T cells during the ex vivo ICS procedure. By comparing the production of the major ROS component $-\mathrm{H}_{2} \mathrm{O}_{2}-$ in purified $\mathrm{Ly}_{6 \mathrm{G}}{ }^{+}$neutrophils and $\mathrm{Ly} 6 \mathrm{G}^{+}$neutrophil-depleted lung tissue cells that were both processed by ICS, we found that $\mathrm{Ly}_{6 \mathrm{G}} \mathrm{G}^{+}$ neutrophils were indeed the primary source of $\mathrm{H}_{2} \mathrm{O}_{2}$ in both naïve and tumor-bearing conditions (Figure 3A). Surprisingly, Ly6G ${ }^{+}$ neutrophils that did not undergo the ICS procedure only produce a 
A

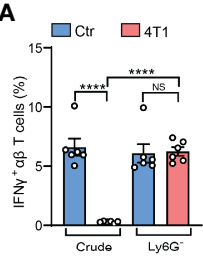

C

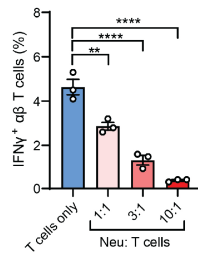

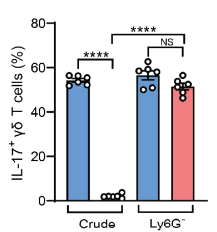

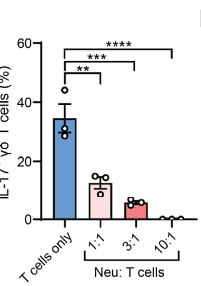

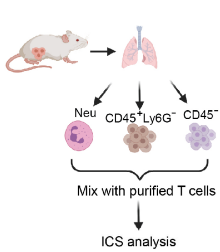

D

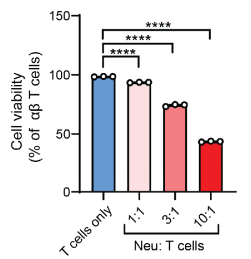

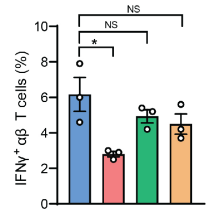

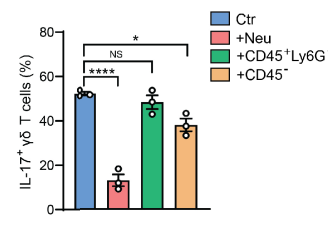

E

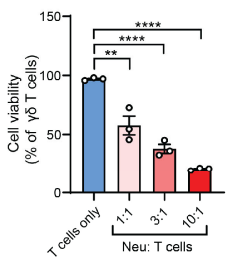

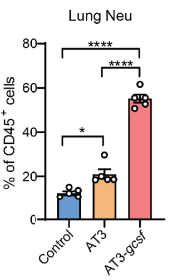

F
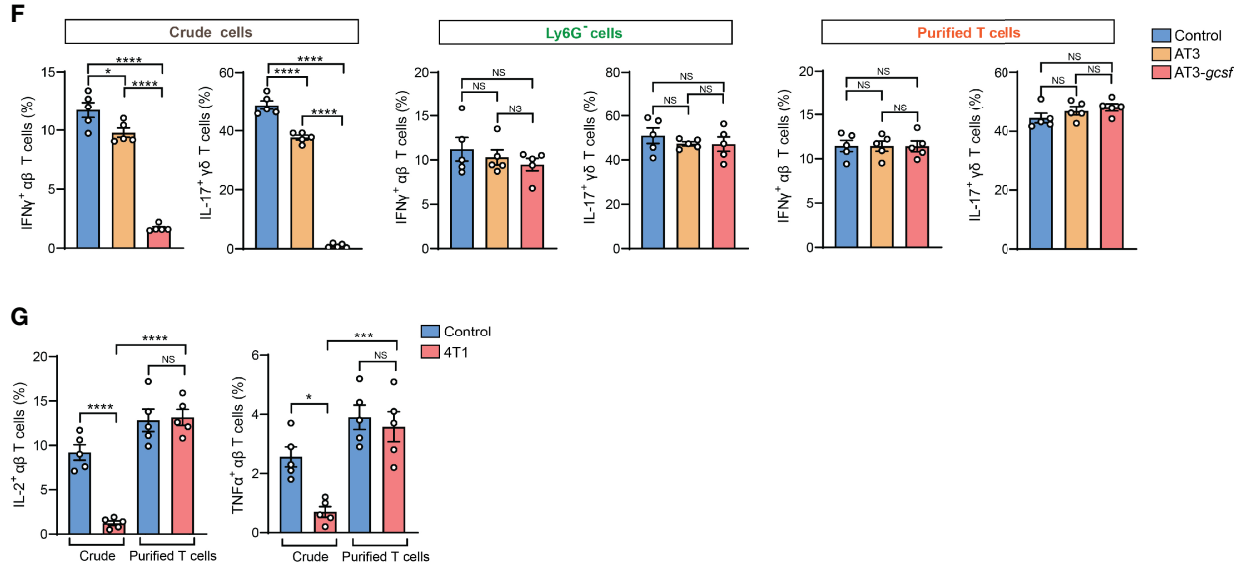

FIGURE 2 | Presence of neutrophils in crude tissue samples accounts for the artifactual results of T cell immunosuppression in tumor-bearing conditions. (A) ICS analysis of the frequencies of lung IFN $\gamma^{+} \alpha \beta$ T cells (left) or IL-17 $\gamma \delta$ T cells (right) from control or 4T1 tumor-bearing mice ( $\mathrm{n}=6$ per group) with or without neutrophil depletion. (B) Purified naïve mice-derived lung T cells were mixed with different types of lung tissue cells (Ly6G ${ }^{+}$neutrophils, $\mathrm{CD}_{4} 5^{+} \mathrm{Ly} 6 \mathrm{G}^{-}$non-neutrophil leukocytes, or CD45- non-leukocyte stromal cells) derived from 4T1 tumor-bearing mice, and the frequencies of IFN $\gamma^{+} \alpha \beta \mathrm{T}$ cells or IL-17 ${ }^{+} \gamma \delta \mathrm{T}$ cells were quantified by ICS. (C, D) Purified naïve mice-derived lung T cells and 4T1 tumor-bearing mice-derived lung neutrophils were mixed together at the indicated ratios and subjected to ICS analysis. The frequencies of IFN $\gamma^{+} \alpha \beta$ T cells or IL-17 $\gamma \delta$ T cells (C) were quantified, and the T cell viabilities (D) were determined by Live/Dead Fixable staining. (E) The percentages of lung neutrophils were compared among control, AT3- and AT3-gcsf tumor-bearing mice ( $n=5$ mice per group). (F) ICS analysis of the frequencies of lung IFN $\gamma^{+} \alpha \beta$ T cells or IL-17 ${ }^{+} \gamma \delta$ T cells in crude samples (left), neutrophil-depleted samples (Ly6G cells; middle), and purified T cell samples (right) in the AT3/AT3-g-csf models ( $n=5$ mice per group). (G) ICS analysis of the frequencies of lung IL-2 ${ }^{+} \alpha \beta$ T cells (left) or TNF $\alpha^{+} \alpha \beta$ T cells (right) in crude samples or in purified T cell samples from control or $4 \mathrm{~T} 1$ tumor-bearing mice ( $\mathrm{n}=5$ per group). Values of $\mathrm{n}$ represent biologically independent animals. Data are mean \pm s.e.m. $P$ values were calculated using one-way ANOVA (A-G). ${ }^{\star} P<0.05 ;{ }^{\star \star} P<0.01$; ${ }^{\star \star \star} P<0.001$; ${ }^{\star \star \star \star} P<0.0001$. NS, not significant.

very low level of $\mathrm{H}_{2} \mathrm{O}_{2}$ (Figure 3B, control group), suggesting that certain ICS reagents may induce ex vivo $\mathrm{Ly}_{6} \mathrm{G}^{+}$neutrophil activation to produce $\mathrm{H}_{2} \mathrm{O}_{2}$.

In ICS analysis, immune cells usually need to be activated by mitogens or antigens to mount cytokine responses prior to immunostaining (2). For $\mathrm{T}$ cells, the commonly used activation agents are phorbol 12-myristate 13-acetate (PMA) and ionomycin, which are a protein kinase $\mathrm{C}$ activator and a calcium ionophore, respectively (15). Although both PMA and ionomycin have been reported to stimulate NET formation and neutrophil apoptosis $(16,17)$, we found that only PMA but not ionomycin was able to induce $\mathrm{H}_{2} \mathrm{O}_{2}$ production in $\mathrm{Ly}_{6} \mathrm{G}^{+}$ neutrophils at the same or less concentrations as used in ICS (Figure 3B). These results indicated that PMA is a primary
ICS agent that activates $\mathrm{Ly}_{6 \mathrm{G}^{+}}$neutrophils to release cytotoxic $\mathrm{H}_{2} \mathrm{O}_{2}$.

We next attempted to abrogate $\mathrm{H}_{2} \mathrm{O}_{2}$ as a strategy for resolving the PMA-related ICS artifact. To this end, catalase, an antioxidant enzyme with a high capacity to rapidly catalyze $\mathrm{H}_{2} \mathrm{O}_{2}$ decomposition (18), was tested. As expected, $\mathrm{H}_{2} \mathrm{O}_{2}$ levels was substantially reduced by catalase in crude lung samples isolated from tumor-bearing mice (Figure 3C). Consequently, addition of catalase in the neutrophil: $\mathrm{T}$ cell co-cultures (Figures 3D, E), or in the crude tissue samples (Figure S5A), significantly mitigated the ICS-associated artifact of $\mathrm{T}$ cell suppression (killing). Using catalase addition as a solution to ICS artifact was also found to be effective for intratumoral $\mathrm{T}$ cell analysis in crude tumor samples (Figures 3F, G), a widely employed 

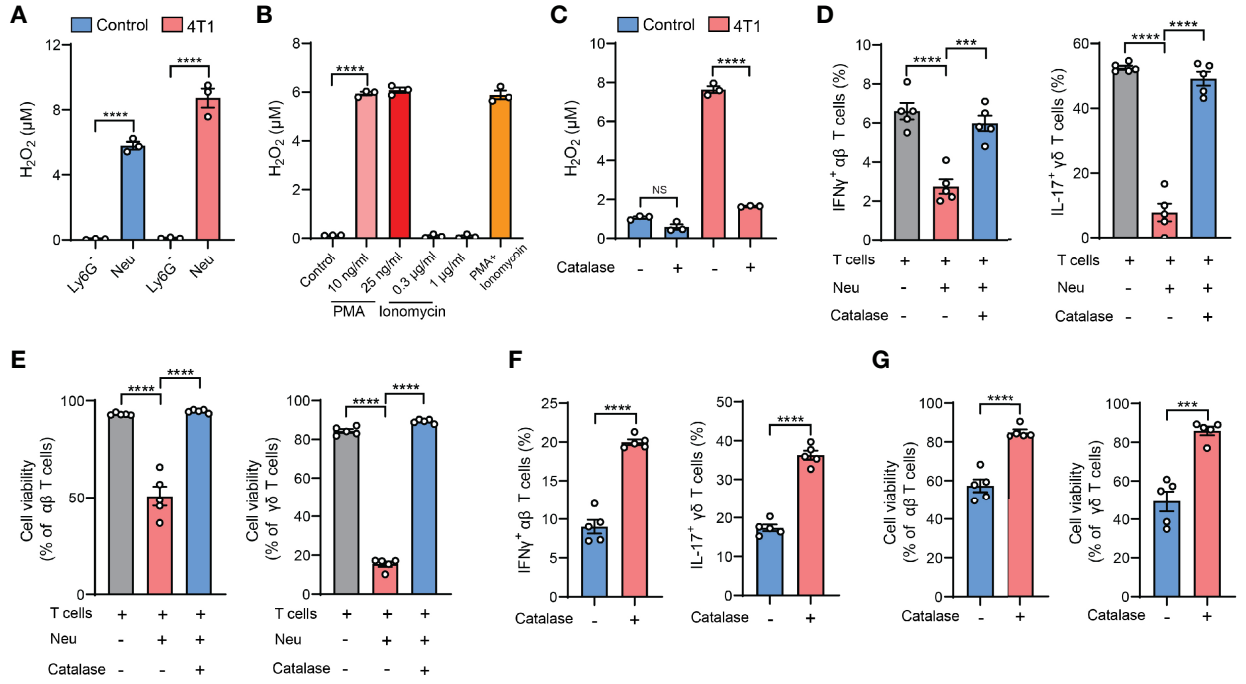

H
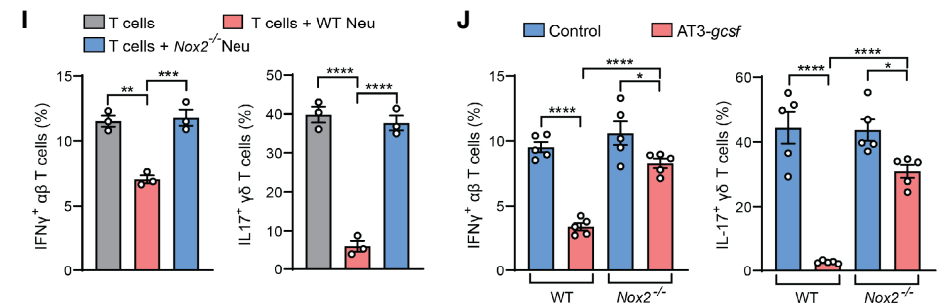

K

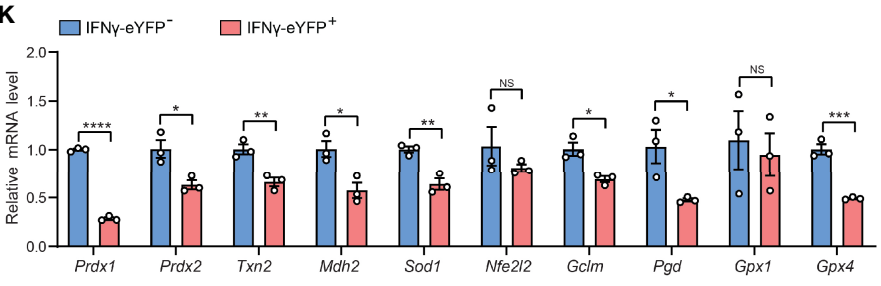

$\mathbf{L}$

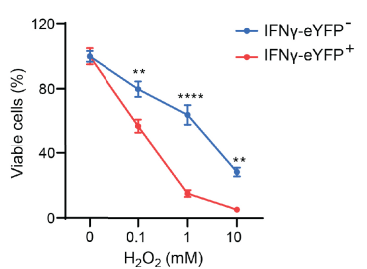

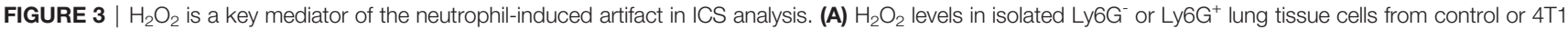
tumor-bearing mice ( $n=3$ per group) were measured after ICS stimulation for 30 minutes at room temperature. (B) $\mathrm{H}_{2} \mathrm{O}_{2}$ levels in lung neutrophils isolated from $4 \mathrm{~T} 1$ tumor-bearing mice $(\mathrm{n}=3)$ were measured after incubation with the indicated concentrations of PMA or ionomycin or cotreatment with PMA (25 ng/ml) + ionomycin (1 $\mu \mathrm{g} / \mathrm{ml}$ ) for 30 minutes at room temperature. (C) $\mathrm{H}_{2} \mathrm{O}_{2}$ levels in crude lung samples derived from control or $4 \mathrm{~T} 1$ tumor-bearing mice were measured after ICS stimulation for 30 minutes at room temperature in the absence or presence of catalase (1000 U/ml). (D, E) Purified naïve mice-derived lung T cells and 4T1 tumorbearing mice-derived lung neutrophils were mixed together in the absence or presence of catalase (1000 U/ml), and then subjected to ICS analysis. The frequencies of IFN $\gamma^{+} \alpha \beta$ T cells or IL-17 $\gamma \delta$ T cells (D) were quantified, and the T cell viabilities (E) were determined by Live/Dead Fixable staining. (F, G) Crude 4T1 tumor samples ( $\mathrm{n}=5$ per group) were subjected to ICS analysis in the absence or presence of catalase $(1000 \mathrm{U} / \mathrm{ml})$. The frequencies of IFN $\gamma^{+} \alpha \beta \mathrm{T}$ cells or IL-17 ${ }^{+} \gamma \delta \mathrm{T}$ cells (F) were quantified, and the T cell viabilities (G) were determined by Live/Dead Fixable staining. (H) $\mathrm{H}_{2} \mathrm{O}_{2}$ levels in isolated Ly6G ${ }^{+}$lung tissue cells from WT or Nox2 ${ }^{-1}$ AT3-gcsf tumor-bearing mice were measured after PMA (25 ng/ml) stimulation for 30 minutes at room temperature. (I) Purified naïve mice-derived lung T cells were

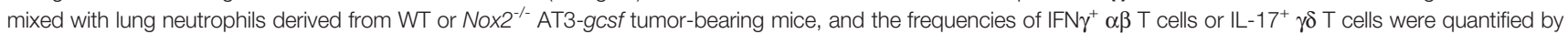
ICS $(n=3)$. (J) ICS analysis of the frequencies of IFN $\gamma^{+} \alpha \beta$ T cells or IL-17 $7^{+} \gamma \delta$ T cells in crude lung samples from WT or Nox2 ${ }^{-/-}$AT3-gcsf tumor-bearing mice $(n=5$ per group). (K) Relative mRNA levels of the indicated antioxidant genes were compared between IFN $\gamma^{-}$and IFN $\gamma^{+}$lung $\alpha \beta T$ cells isolated from IFN $\gamma$-eYFP mice ( $\left.n=5\right)$. (L) Susceptibility of IFN $\gamma^{-}$and IFN $\gamma^{+}$lung $\alpha \beta$ T cells, isolated from IFN $\gamma$-eYFP mice $(n=3)$, to the indicated concentration of $\mathrm{H}_{2} \mathrm{O}_{2}$ for 2 hours. Values of $n$ represent biologically independent animals. Data are mean \pm s.e.m. $P$ values were calculated using unpaired $t$-test (F, G, K) or one-way ANOVA (A-E, H-J) or two-way ANOVA (L). ${ }^{\star} P<0.05 ;{ }^{\star \star} P<0.01 ;{ }^{\star \star \star} P<0.001 ;{ }^{\star \star \star \star} P<0.0001$. NS, not significant.

measurement to evaluate immunosuppression within the tumor microenvironment. To further affirm the role of $\mathrm{H}_{2} \mathrm{O}_{2}$ in ICSassociated artifact, we utilized $\mathrm{Nox}^{-/-}$mice which lack the expression of NADPH oxidase 2, a key enzyme in $\mathrm{H}_{2} \mathrm{O}_{2}$ generation (19). Of note, Nox2 deficiency caused a nearly abolished $\mathrm{H}_{2} \mathrm{O}_{2}$ production in PMA-stimulated $\mathrm{Ly}_{6 \mathrm{G}}{ }^{+}$ neutrophils (Figure 3H). In line with this $\mathrm{H}_{2} \mathrm{O}_{2}$ change, in the neutrophil-T cell co-culture system, neutrophil-mediated suppression of IFN $\gamma^{+}$and IL- $17^{+} \mathrm{T}$ cells was largely reversed by Nox2 deficiency in $\mathrm{Ly}_{6} \mathrm{G}^{+}$neutrophils, as measured by ICS 
(Figure 3I). Furthermore, the artifactual T cell suppression during ICS analysis of crude tissue (lung) samples was significantly mitigated by the host Nox2 deficiency in the AT3-gcsf tumor model (Figure 3J). Taken together, $\mathrm{H}_{2} \mathrm{O}_{2}$ was revealed as the key mediator of neutrophil-induced artifact in ICS analysis, and addition of catalase in the ICS procedure was effective in alleviating the $\mathrm{H}_{2} \mathrm{O}_{2}$-associated artifact, representing an improvement to the ICS method when using crude tissue samples containing neutrophils.

Although the mechanisms underlying $\mathrm{H}_{2} \mathrm{O}_{2}$ /ROS-mediated killing of cytokine-expressing $\mathrm{T}$ cells [representing the activated T cells (20)] need to be further determined, it has been previously reported that IL- $17^{+} \gamma \delta \mathrm{T}$ cells are susceptible to ROS in the tumor microenvironment due to their low-level expression of the antioxidant glutathione (21). Using the IFN $\gamma$-eYFP reporter mice, we found that the IFN $\gamma^{+} \mathrm{T}$ cells similarly express lower levels of a series of antioxidant genes and are more sensitive to $\mathrm{H}_{2} \mathrm{O}_{2}$-induced cell killing, in comparison to their IFN $\gamma^{-}$ counterparts (Figures 3K, L). Therefore, the selective killing of cytokine-expressing $\mathrm{T}$ cells by $\mathrm{H}_{2} \mathrm{O}_{2} / \mathrm{ROS}$ is likely due to their low expression of antioxidants. In addition, $\mathrm{H}_{2} \mathrm{O}_{2} / \mathrm{ROS}$ was known to mediate NETs formation in neutrophils upon PMA stimulation (22-24), and T cell functions have also been reported to be altered by NETs (25-27). Future efforts need to be made to characterize whether and how NETs play a role in $\mathrm{H}_{2} \mathrm{O}_{2}$ /ROSmediated ex vivo T cell modulation in ICS analysis of neutrophilcontaining samples.

\section{The Neutrophil-Induced Artifact Occurs in Other Host Neutrophilia Conditions Than Tumor Models}

Based on above findings derived from tumor models, we next asked whether the neutrophil-induced ICS artifact is generalized to other host neutrophilia conditions than tumor models. To this end, we included two experimental models by exogenous injection of GCSF, the neutrophil-specific growth factor, or exogenous injection of lipopolysaccharide (LPS) which stimulates systemic inflammatory responses (28). Upon G-CSF administration, mice expectedly develop neutrophilia, marked by a striking elevation of Ly $6 \mathrm{G}^{+}$neutrophils in different organs and blood circulation (Figures 4A, B). Using ICS analysis of the crude spleen and lung tissue samples, we again detected the artifactual suppression of IFN $\gamma^{+}$and IL- $17^{+} \mathrm{T}$ cells in G-CSF-injected mice, which was not observed using the same crude samples depleted of $\mathrm{Ly}_{6 \mathrm{G}}{ }^{+}$ neutrophils (Figure 4C). Similarly, host neutrophilia was remarkably induced in the LPS model (Figures 4D, E), and the presence or absence of $\mathrm{Ly}_{6} \mathrm{G}^{+}$neutrophils in the crude spleen and lung tissue samples again determined the occurrence of $\mathrm{T}$ cell "suppression" or not as analyzed by ICS (Figure 4F). Hence, $\mathrm{Ly}_{6} \mathrm{G}^{+}$ neutrophil-associated ICS artifact occurs at different pathological contexts in which host neutrophilia was induced.

\section{The ICS-Associated Artifact Occurs in Human Immune Cell Analyses}

In the past decade, cancer immunotherapeutic targeting $\mathrm{T}$ cell immunosuppression has emerged as one of the most promising treatments in managing a diversity of human cancer types (29). As neutrophils are the most abundant immune cells in humans (30), our findings from the mouse models led us to raise a concern that the artifactual immunosuppression readouts from ICS analysis of human patient specimens could potentially mislead the development of effective immunotherapies. To understand whether neutrophil-associated ICS artifact also arises in analysis of human immune cells, we exploited the humanized $\mathrm{NSG}^{\mathrm{TM}}$ SGM3 mice (NSG mice expressing human stem cell factor, granulocyte macrophage colony-stimulating factor and IL-3) in which human $\mathrm{CD} 34^{+}$hematopoietic stem/progenitor cells had been engrafted and developed into functional human immune system including human neutrophils and T cells (31). Upon a successful xenograft of human MDA-MB-231 breast tumor cells, human neutrophils and $\mathrm{T}$ cells were isolated. Consistent with the mouse system, human neutrophils were able to release $\mathrm{H}_{2} \mathrm{O}_{2}$ after stimulation by PMA but not ionomycin (Figure 5A). By ICS analysis of human $\mathrm{T}$ cells co-cultured with human neutrophils, a prominent neutrophil-mediated suppression of both IFN $\gamma^{+}$and IL$17^{+} \mathrm{T}$ cells was found in both spleen and lung samples (Figure 5B). This suppression was also identified to occur in other human cytokines including IL-2 and TNF $\alpha$, which was largely reversed by addition of catalase (Figures 5C, D). Collectively, these results suggested that the ICS-associated artifact could similarly exist in human immune cell analysis.

ICS analysis of the peripheral blood (PB) samples is a common test method in evaluation of the immune responses in human patients with cancer, infection and inflammatory diseases (32-34). In our mouse model of 4T1 breast cancer, PB manifests the same artifact (tumor-induced $\mathrm{T}$ cell suppression) when assessing IFN $\gamma^{+} \mathrm{CD}^{+} \mathrm{T}$ cells by ICS, while such an "immunosuppression" was not concluded using the IFN $\gamma$-eYFP reporter mice by living cell immunostaining and flow cytometric analysis (Figure S5B). Using the humanized mice, we found that addition of catalase in the PB samples significantly increased the percentages of IFN $\gamma^{+}$and IL-17 $7^{+}$human $\mathrm{T}$ cells as detected by ICS, suggesting a possible reaction between human neutrophils and human $\mathrm{T}$ cells during the sample activation stage in ICS (Figure 5E). Thus, special attention should be paid when PMAinvolved ICS method is used in patients' blood sample analyses for $\mathrm{T}$ cell responses in clinical studies as PMA induces robust ROS production and cytotoxicity of human neutrophils according to our results and others' studies $(35,36)$.

\section{DISCUSSION}

In this study, we defined a previously unrecognized issue with ICS, a widely used cytokine-determining method for $\mathrm{T}$ and other immune cells. When the ICS samples contain neutrophils, the T cell activation agent PMA also stimulates neutrophils, which in turn release $\mathrm{H}_{2} \mathrm{O}_{2}$ and kill cytokine-expressing $\mathrm{T}$ cells. This causes a robust but artifactual $\mathrm{T}$ cell immunosuppression (Figure 5F). Although other approaches such as qPCR, enzyme-linked immunosorbent spot (ELISpot) assay, and ELISA can be utilized to detect cytokine production in immune cells, ICS remains the 
A

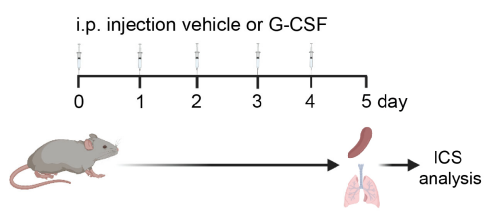

B

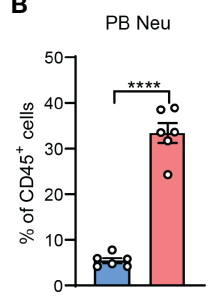

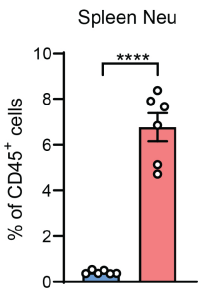

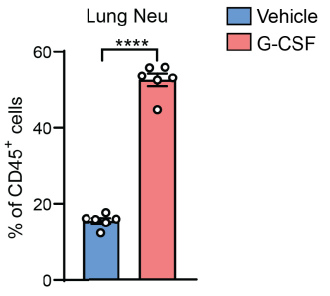

C

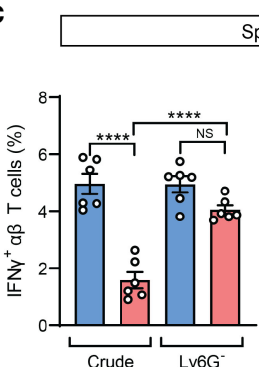

Spleen sample
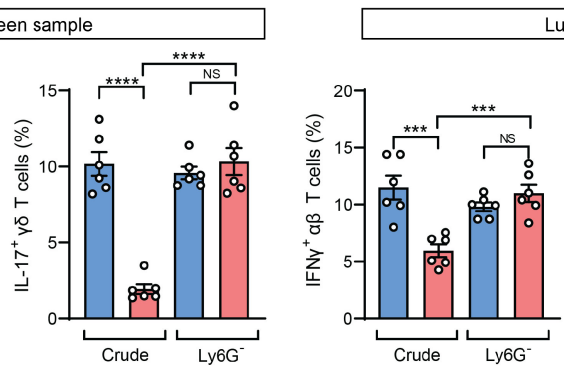

ung sample
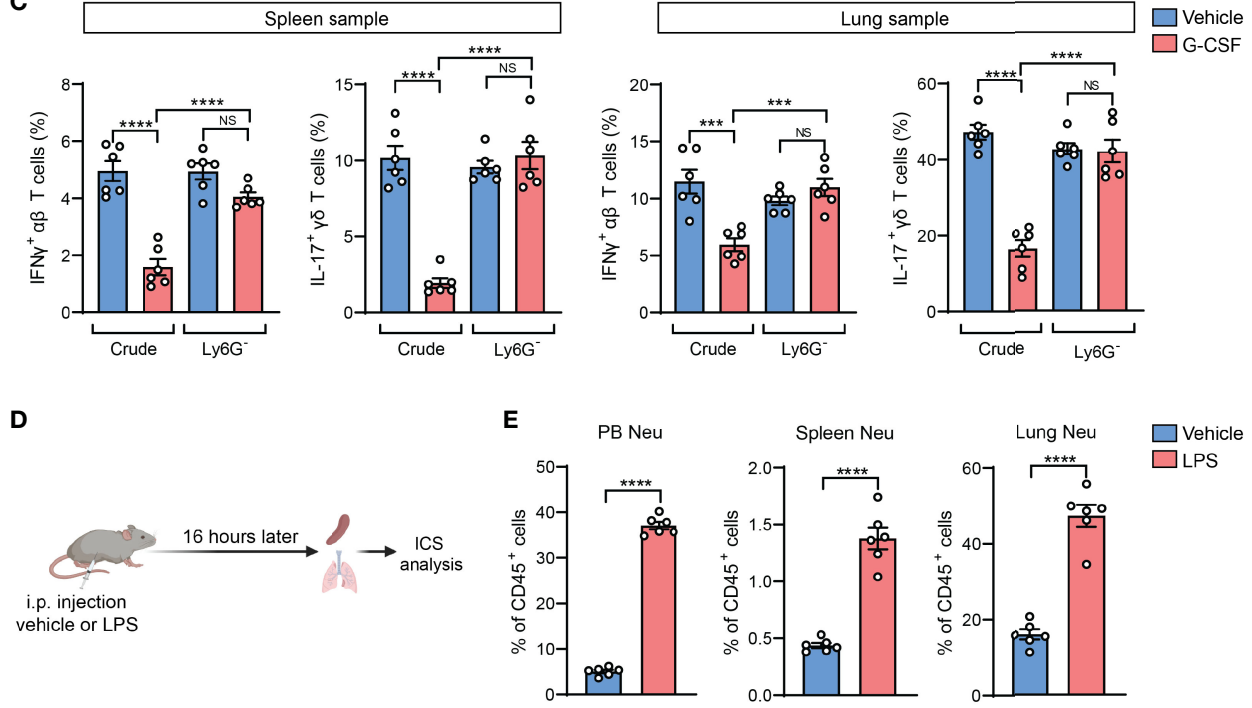

$\mathbf{F}$

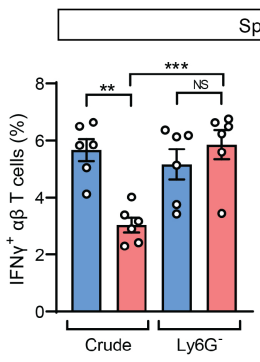

Spleen sample
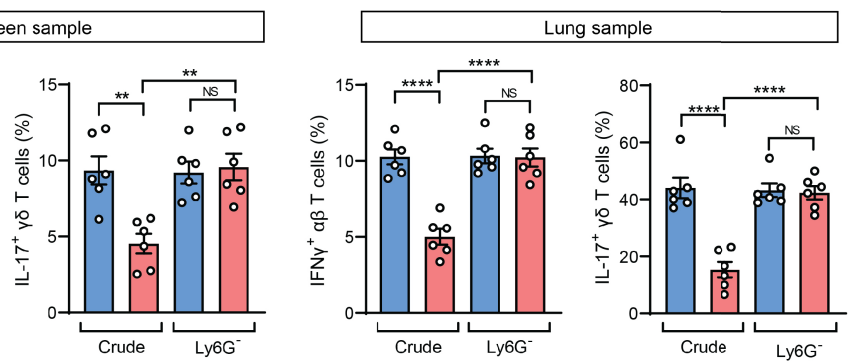

FIGURE 4 | The neutrophil-induced artifact occurs in other host neutrophilia conditions than tumor models. (A-C), As depicted in (A) the mice were received i.p. injection of recombinant mouse G-CSF $(0.125 \mathrm{mg} / \mathrm{kg})$ or vehicle for 5 consecutive days. The percentages of neutrophils $\left(C D 45^{+} \mathrm{CD} 11 \mathrm{~b}^{+} \mathrm{Ly} 6 \mathrm{G}^{+}\right)$in peripheral blood (PB), spleen or lungs were quantified (B). The frequencies of IFN $\gamma^{+} \alpha \beta$ T cells or IL- $17^{+} \gamma \delta \mathrm{T}$ cells in spleen or lung samples ( $\mathrm{n}=6 \mathrm{per}$ group) with or without neutrophil depletion, were detected ICS and flow cytometry (C). (D-F), As depicted in (D) the mice were received i.p. injection of LPS (2.5 mg/kg) or vehicle. 16 hours later, the percentages of neutrophils in PB, spleen or lung were quantified (E). The frequencies of IFN $\gamma^{+} \alpha \beta T$ cells or IL-17 ${ }^{+} \gamma \delta T$ cells in spleen or lung samples ( $\mathrm{n}=6$ per group) with or without neutrophil depletion, were detected by ICS and flow cytometry (F). Values of $n$ represent biologically independent animals. Data are mean \pm s.e.m. $P$ values were calculated using unpaired $t$-test (B, E) or one-way ANOVA (C, F). ${ }^{\star \star} P<0.01 ;{ }^{\star \star \star} P<0.001 ;{ }^{\star \star \star \star} P<0.0001$. NS, not significant.

most prevalent tool to determine the intracellular cytokines in individual cells isolated from tissue samples. Based on our results, we therefore recommend conducting neutrophil depletion or T cell purification in ICS analysis, and including complementary methods in measurement of cellular cytokine levels in experimental and clinical blood and tissue samples containing neutrophils. Besides those, other T cell activation methods than using PMA, such as antiCD3 plus anti-CD28 antibodies and antigen-specific $\mathrm{T}$ cell activation, which do not stimulate neutrophils, also avoided the
PMA-associated artifact (Figure S6). Thus, our improvements to the ICS protocol and proposed alternative methods would benefit a wide array of basic and clinical research.

Such ICS artifact and its resulting false positive result of T cell immunosuppression has the potential to greatly misguide cancer immunology and other immunological research. Cancer-related inflammation is well known to elicit both host neutrophilia and $\mathrm{T}$ cell immunosuppression in a wide variety of cancer types $(9,37$, 38). This ICS-associated artifact could lead to overinterpretation of 
A

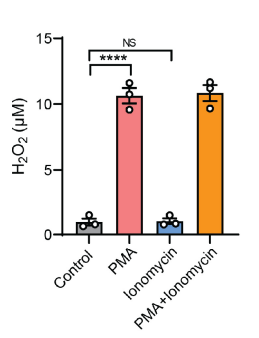

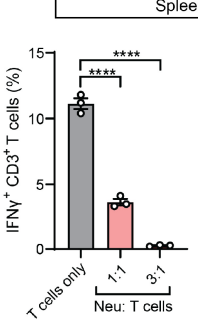

Spleen sample

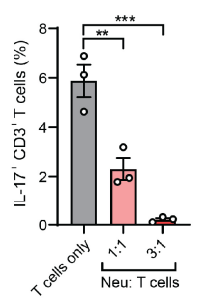

C
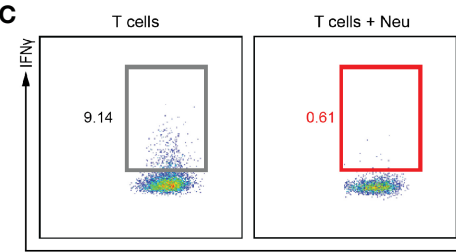

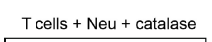

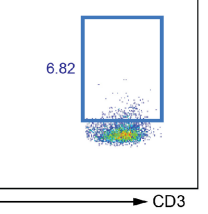
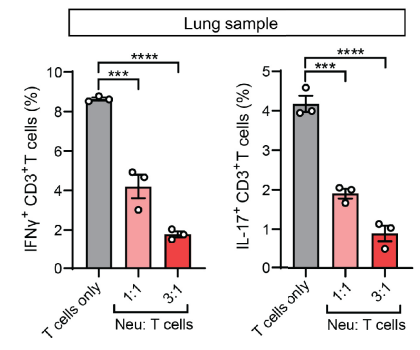

E

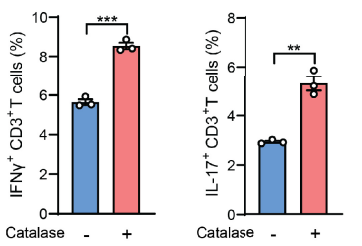

D

$\square T$ cells $\square$ T cells + Neu
$\square$ T cells + Neu + catalase
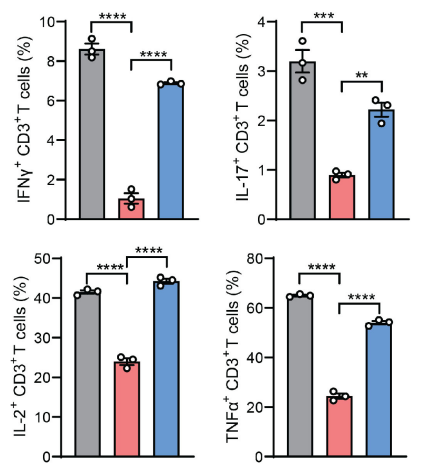

$\mathbf{F}$

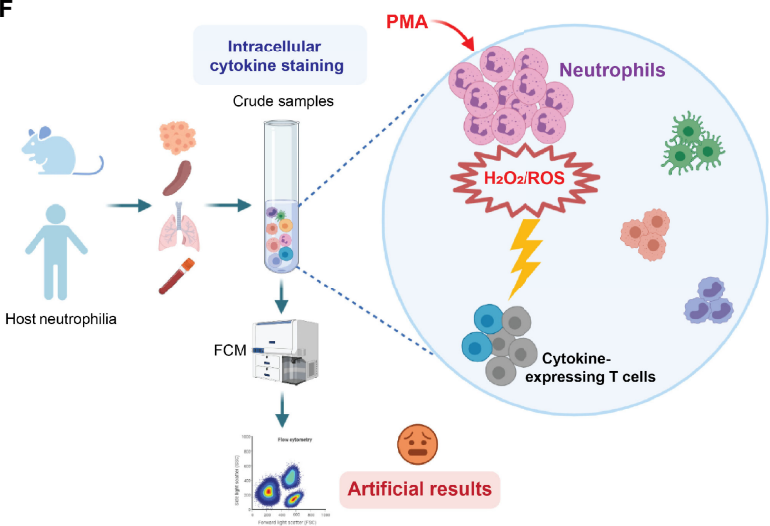

FIGURE 5 | The ICS-associated artifact occurs in human immune cell analyses. (A) $\mathrm{H}_{2} \mathrm{O}_{2}$ levels in human neutrophils isolated from lung tissues of MDA-MB-231 tumor-bearing Hu-CD34 ${ }^{+}$mice $(\mathrm{n}=3)$ were measured after incubation with PMA $(25 \mathrm{ng} / \mathrm{ml})$ or ionomycin $(1 \mu \mathrm{g} / \mathrm{ml})$ or co-treatment with PMA $(25 \mathrm{ng} / \mathrm{ml})+$ ionomycin $(1 \mathrm{\mu g} / \mathrm{ml})$ for 30 minutes at room temperature. (B) Human T cells and neutrophils were isolated from spleen or lung tissues of MDA-MB-231 tumor-bearing Hu$\mathrm{CD}_{4}{ }^{+}$mice $(\mathrm{n}=3)$, mixed together at the indicated ratios and then subjected to ICS analysis. The frequencies of IFN $\gamma^{+} \mathrm{CD}^{+} \mathrm{T}_{\mathrm{Cell}}$ or IL-17 ${ }^{+} \mathrm{CD} 3^{+} \mathrm{T}$ cells were quantified. (C, D) Human T cells and neutrophils were isolated from lung tissues of MDA-MB-231 tumor-bearing Hu-CD34 ${ }^{+}$mice ( $\mathrm{n}=3$ ), mixed together in the absence or presence of catalase $(1000 \mathrm{U} / \mathrm{ml})$, and then subjected to ICS analysis. The frequencies of IFN $\gamma^{+} \mathrm{CD} 3^{+} \mathrm{T}$ cells, IL-17 $7^{+} \mathrm{CD} 3^{+} \mathrm{T}$ cells, IL-2 ${ }^{+} \mathrm{CD} 3^{+} \mathrm{T}$ cells and $\mathrm{TNF} \alpha^{+} \mathrm{CD}^{+} \mathrm{T}$ cells were quantified. (E) Crude PB samples derived from MDA-MB-231 tumor-bearing Hu-CD34 ${ }^{+}$mice ( $\mathrm{n}=3$ ) were subjected to ICS analysis in the absence or presence of catalase (1000 U/ml). The frequencies of IFN $\gamma^{+} \mathrm{CD}^{+} \mathrm{T}$ cells and IL-17 $7^{+} \mathrm{CD} 3^{+} \mathrm{T}$ cells were quantified. (F) A proposed model: in crude tissue samples ICS analysis, the T cell activation agent PMA simultaneously stimulates neutrophils to release $\mathrm{H}_{2} \mathrm{O}_{2} / \mathrm{ROS}$, which kills cytokine-expressing $T$ cells, leading to an artifactual result of $\mathrm{T}$ cell immunosuppression. Values of $\mathrm{n}$ represent biologically independent animals. Data are mean \pm s.e.m. $P$ values were calculated using one-way ANOVA (A, B, D) or unpaired $t$-test (E). ${ }^{\star \star} P<0.01 ;{ }^{\star \star \star} P<0.001$; ${ }^{\star \star \star \star} P<0.0001$. NS, not significant.

$\mathrm{T}$ cell immunosuppression caused by cancer-associated inflammation in both preclinical models and clinical sample analyses. Further, $\mathrm{T}$ cell immunosuppression is a fundamental target of cancer immunotherapy $(39,40)$, and an artificial immunosuppression readout could potentially hinder the development of effective immunotherapeutics. In other immunological research such as the emerging COVID-19 studies, blood samples have been routinely used for immune profiling (41, 42), and host neutrophilia and $\mathrm{T}$ cell immunosuppression were both reported in severe COVID-19 patients $(43,44)$. Thus, our results highlight that careful attention should be paid in studies using COVID-19 patient blood samples for ICS analysis.

\section{DATA AVAILABILITY STATEMENT}

The original contributions presented in the study are included in the article/Supplementary Material. Further inquiries can be directed to the corresponding author.

\section{ETHICS STATEMENT}

The animal study was reviewed and approved by Institutional Animal Care and Use Committee at The Jackson Laboratory. 


\section{AUTHOR CONTRIBUTIONS}

GR, ZG, and QL conceived the project, designed the study and performed the data analysis. ZG and QL performed the in vivo and in vitro studies, statistical analysis and generated the figures. JS did animal work and mouse colony management. GR, ZG, and QL interpreted the data and wrote the manuscript. All authors contributed to the article and approved the submitted version.

\section{FUNDING}

This work was supported by grants from the National Institutes of Health (R00-CA188093, R37-CA237307, R01CA251433 and P30-CA034196 to GR). QL was supported by the Pyewacket Fund at The Jackson Laboratory.

\section{REFERENCES}

1. Lovelace P, Maecker HT. Multiparameter Intracellular Cytokine Staining. Methods Mol Biol (2011) 699:165-78. doi: 10.1007/978-1-61737-950-5_8

2. Foster B, Prussin C, Liu F, Whitmire JK, Whitton JL. Detection of Intracellular Cytokines by Flow Cytometry. Curr Protoc Immunol (2007). Chapter 6:Unit 6 24. doi: 10.1002/0471142735.im0624s78

3. Nicolas-Avila JA, Adrover JM, Hidalgo A. Neutrophils in Homeostasis, Immunity, and Cancer. Immunity (2017) 46(1):15-28. doi: 10.1016/ j.immuni.2016.12.012

4. Schroder K, Hertzog PJ, Ravasi T, Hume DA. Interferon-Gamma: An Overview of Signals, Mechanisms and Functions. J Leukoc Biol (2004) 75(2):163-89. doi: $10.1189 / \mathrm{jlb} .0603252$

5. Reinhardt RL, Liang HE, Locksley RM. Cytokine-Secreting Follicular T Cells Shape the Antibody Repertoire. Nat Immunol (2009) 10(4):385-93. doi: 10.1038/ni.1715

6. Papotto PH, Ribot JC, Silva-Santos B. IL-17(+) Gammadelta T Cells as KickStarters of Inflammation. Nat Immunol (2017) 18(6):604-11. doi: 10.1038/ ni. 3726

7. Roark CL, Simonian PL, Fontenot AP, Born WK, O'Brien RL. Gammadelta T Cells: An Important Source of IL-17. Curr Opin Immunol (2008) 20(3):353-7. doi: 10.1016/j.coi.2008.03.006

8. Kowanetz M, Wu X, Lee J, Tan M, Hagenbeek T, Qu X, et al. GranulocyteColony Stimulating Factor Promotes Lung Metastasis Through Mobilization of Ly6G+Ly6C+ Granulocytes. Proc Natl Acad Sci USA (2010) 107 (50):21248-55. doi: 10.1073/pnas.1015855107

9. Shaul ME, Fridlender ZG. Tumour-Associated Neutrophils in Patients With Cancer. Nat Rev Clin Oncol (2019) 16(10):601-20. doi: 10.1038/s41571-0190222-4

10. Li P, Lu M, Shi J, Gong Z, Hua L, Li Q, et al. Lung Mesenchymal Cells Elicit Lipid Storage in Neutrophils That Fuel Breast Cancer Lung Metastasis. Nat Immunol (2020) 21(11):1444-55. doi: 10.1038/s41590-020-0783-5

11. Nemeth T, Sperandio M, Mocsai A. Neutrophils as Emerging Therapeutic Targets. Nat Rev Drug Discov (2020) 19(4):253-75. doi: 10.1038/s41573-0190054-z

12. Ley K, Hoffman HM, Kubes P, Cassatella MA, Zychlinsky A, Hedrick CC, et al. Neutrophils: New Insights and Open Questions. Sci Immunol (2018) 3 (30). doi: 10.1126/sciimmunol.aat4579

13. Nguyen GT, Green ER, Mecsas J. Neutrophils to the ROScue: Mechanisms of NADPH Oxidase Activation and Bacterial Resistance. Front Cell Infect Microbiol (2017) 7:373. doi: 10.3389/fcimb.2017.00373

14. Walker C, Bettens F, Pichler WJ. T Cell Activation by Cross-Linking AntiCD3 Antibodies With Second Anti-T Cell Antibodies: Dual Antibody CrossLinking Mimics Physical Monocyte Interaction. Eur J Immunol (1987) 17 (11):1611-8. doi: 10.1002/eji.1830171114

15. Crawford TQ, Jalbert E, Ndhlovu LC, Barbour JD. Concomitant Evaluation of PMA+ionomycin-Induced Kinase Phosphorylation and Cytokine Production

\section{ACKNOWLEDGMENTS}

We thank Dr. Scott I. Abrams (Roswell Park Comprehensive Cancer Center) for providing the AT3 breast cancer cell line, and thank Dr. Robert A. Weinberg (Whitehead Institute for Biomedical Research) for providing the lentiviral vector expressing the mouse G-CSF. We appreciate Dr. Iiro Taneli Helenius for his critical editing of the manuscript and also thank the assistance from The Jackson Laboratory Scientific Service.

\section{SUPPLEMENTARY MATERIAL}

The Supplementary Material for this article can be found online at: https://www.frontiersin.org/articles/10.3389/fimmu.2022.759188/ full\#supplementary-material

in T Cell Subsets by Flow Cytometry. Cytometry A (2014) 85(3):268-76. doi: 10.1002/cyto.a.22444

16. Karlsson A, Nixon JB, McPhail LC. Phorbol Myristate Acetate Induces Neutrophil NADPH-Oxidase Activity by Two Separate Signal Transduction Pathways: Dependent or Independent of Phosphatidylinositol 3-Kinase. J Leukoc Biol (2000) 67(3):396-404. doi: 10.1002/jlb.67.3.396

17. Dahlgren C, Karlsson A. Ionomycin-Induced Neutrophil NADPH Oxidase Activity Is Selectively Inhibited by the Serine Protease Inhibitor Diisopropyl Fluorophosphate. Antioxid Redox Signal (2002) 4(1):17-25. doi: 10.1089/ 152308602753625816

18. Apel K, Hirt H. Reactive Oxygen Species: Metabolism, Oxidative Stress, and Signal Transduction. Annu Rev Plant Biol (2004) 55:373-99. doi: 10.1146/ annurev.arplant.55.031903.141701

19. Pollock JD, Williams DA, Gifford MA, Li LL, Du X, Fisherman J, et al. Mouse Model of X-Linked Chronic Granulomatous Disease, an Inherited Defect in Phagocyte Superoxide Production. Nat Genet (1995) 9(2):202-9. doi: 10.1038/ ng0295-202

20. Raphael I, Nalawade S, Eagar TN, Forsthuber TG. T Cell Subsets and Their Signature Cytokines in Autoimmune and Inflammatory Diseases. Cytokine (2015) 74(1):5-17. doi: 10.1016/j.cyto.2014.09.011

21. Mensurado S, Rei M, Lanca T, Ioannou M, Goncalves-Sousa N, Kubo H, et al. Tumor-Associated Neutrophils Suppress Pro-Tumoral IL-17+ Gammadelta T Cells Through Induction of Oxidative Stress. PloS Biol (2018) 16(5):e2004990. doi: 10.1371/journal.pbio.2004990

22. Behnen M, Moller S, Brozek A, Klinger M, Laskay T. Extracellular Acidification Inhibits the ROS-Dependent Formation of Neutrophil Extracellular Traps. Front Immunol (2017) 8:184. doi: 10.3389/fimmu.2017.00184

23. Bjornsdottir H, Welin A, Michaelsson E, Osla V, Berg S, Christenson K, et al. Neutrophil NET Formation Is Regulated From the Inside by Myeloperoxidase-Processed Reactive Oxygen Species. Free Radic Biol Med (2015) 89:1024-35. doi: 10.1016/j.freeradbiomed.2015.10.398

24. Sollberger G, Tilley DO, Zychlinsky A. Neutrophil Extracellular Traps: The Biology of Chromatin Externalization. Dev Cell (2018) 44(5):542-53. doi: 10.1016/j.devcel.2018.01.019

25. Kaltenmeier C, Yazdani HO, Morder K, Geller DA, Simmons RL, Tohme S. Neutrophil Extracellular Traps Promote T Cell Exhaustion in the Tumor Microenvironment. Front Immunol (2021) 12:785222. doi: 10.3389/fimmu.2021.785222

26. Tillack K, Breiden P, Martin R, Sospedra M. T Lymphocyte Priming by Neutrophil Extracellular Traps Links Innate and Adaptive Immune Responses. J Immunol (2012) 188(7):3150-9. doi: 10.4049/jimmunol.1103414

27. Wang H, Zhang H, Wang Y, Brown ZJ, Xia Y, Huang Z, et al. Regulatory TCell and Neutrophil Extracellular Trap Interaction Contributes to Carcinogenesis in Non-Alcoholic Steatohepatitis. J Hepatol (2021) 75 (6):1271-83. doi: 10.1016/j.jhep.2021.07.032

28. Seemann S, Zohles F, Lupp A. Comprehensive Comparison of Three Different Animal Models for Systemic Inflammation. J BioMed Sci (2017) 24(1):60. doi: 10.1186/s12929-017-0370-8 
29. Waldman AD, Fritz JM, Lenardo MJ. A Guide to Cancer Immunotherapy: From T Cell Basic Science to Clinical Practice. Nat Rev Immunol (2020) 20 (11):651-68. doi: 10.1038/s41577-020-0306-5

30. Ng LG, Ostuni R, Hidalgo A. Heterogeneity of Neutrophils. Nat Rev Immunol (2019) 19(4):255-65. doi: 10.1038/s41577-019-0141-8

31. Ishikawa F, Yasukawa M, Lyons B, Yoshida S, Miyamoto T, Yoshimoto G, et al. Development of Functional Human Blood and Immune Systems in NOD/SCID/IL2 Receptor \{Gamma\} Chain(Null) Mice. Blood (2005) 106 (5):1565-73. doi: 10.1182/blood-2005-02-0516

32. Tjin EP, Konijnenberg D, Krebbers G, Mallo H, Drijfhout JW, Franken KL, et al. T-Cell Immune Function in Tumor, Skin, and Peripheral Blood of Advanced Stage Melanoma Patients: Implications for Immunotherapy. Clin Cancer Res (2011) 17(17):5736-47. doi: 10.1158/1078-0432.CCR-11-0230

33. Morita Y, Yamamura M, Kawashima M, Harada S, Tsuji K, Shibuya K, et al. Flow Cytometric Single-Cell Analysis of Cytokine Production by CD4+ T Cells in Synovial Tissue and Peripheral Blood From Patients With Rheumatoid Arthritis. Arthritis Rheum (1998) 41(9):1669-76. doi: 10.1002/ 1529-0131(199809)41:9<1669::AID-ART19>3.0.CO;2-G

34. Le Bert N, Tan AT, Kunasegaran K, Tham CYL, Hafezi M, Chia A, et al. SARSCoV-2-Specific T Cell Immunity in Cases of COVID-19 and SARS, and Uninfected Controls. Nature (2020) 584(7821):457-62. doi: 10.1038/s41586020-2550-z

35. Chen MS, Lin WC, Yeh HT, Hu CL, Sheu SM. Propofol Specifically Reduces PMA-Induced Neutrophil Extracellular Trap Formation Through Inhibition of P-ERK and HOCl. Life Sci (2019) 221:178-86. doi: 10.1016/ j.lfs.2019.02.030

36. Tsan MF, Denison RC. Phorbol Myristate Acetate-Induced Neutrophil Autotoxicity. A Comparison With H2O2 Toxicity. Inflammation (1980) 4 (4):371-80. doi: 10.1007/BF00916048

37. Grivennikov SI, Greten FR, Karin M. Immunity, Inflammation, and Cancer. Cell (2010) 140(6):883-99. doi: 10.1016/j.cell.2010.01.025

38. Nakamura K, Smyth MJ. Myeloid Immunosuppression and Immune Checkpoints in the Tumor Microenvironment. Cell Mol Immunol (2020) 17 (1):1-12. doi: 10.1038/s41423-019-0306-1
39. Saleh R, Elkord E. Acquired Resistance to Cancer Immunotherapy: Role of Tumor-Mediated Immunosuppression. Semin Cancer Biol (2020) 65:13-27. doi: 10.1016/j.semcancer.2019.07.017

40. Tormoen GW, Crittenden MR, Gough MJ. Role of the Immunosuppressive Microenvironment in Immunotherapy. Adv Radiat Oncol (2018) 3(4):520-6. doi: 10.1016/j.adro.2018.08.018

41. Mathew D, Giles JR, Baxter AE, Oldridge DA, Greenplate AR, Wu JE, et al. Deep Immune Profiling of COVID-19 Patients Reveals Distinct Immunotypes With Therapeutic Implications. Science (2020) 369(6508). doi: 10.1126/science.abc8511

42. Varchetta S, Mele D, Oliviero B, Mantovani S, Ludovisi S, Cerino A, et al. Unique Immunological Profile in Patients With COVID-19. Cell Mol Immunol (2021) 18(3):604-12. doi: 10.1038/s41423-020-00557-9

43. Wang J, Li Q, Yin Y, Zhang Y, Cao Y, Lin X, et al. Excessive Neutrophils and Neutrophil Extracellular Traps in COVID-19. Front Immunol (2020) 11:2063. doi: 10.3389/fimmu.2020.02063

44. Cao X. COVID-19: Immunopathology and its Implications for Therapy. Nat Rev Immunol (2020) 20(5):269-70. doi: 10.1038/s41577-020-0308-3

Conflict of Interest: The authors declare that the research was conducted in the absence of any commercial or financial relationships that could be construed as a potential conflict of interest.

Publisher's Note: All claims expressed in this article are solely those of the authors and do not necessarily represent those of their affiliated organizations, or those of the publisher, the editors and the reviewers. Any product that may be evaluated in this article, or claim that may be made by its manufacturer, is not guaranteed or endorsed by the publisher.

Copyright (c) 2022 Gong, Li, Shi and Ren. This is an open-access article distributed under the terms of the Creative Commons Attribution License (CC BY). The use, distribution or reproduction in other forums is permitted, provided the original author(s) and the copyright owner(s) are credited and that the original publication in this journal is cited, in accordance with accepted academic practice. No use, distribution or reproduction is permitted which does not comply with these terms. 